\title{
Pregnant, uninfected, stressed, and confined in the COVID-19 period: what can we expect in the near future?
}

\author{
(iD) Pedro Castro ${ }^{\mathbf{1} 2}$ \\ (iD) Carolina Narciso ${ }^{1}$ \\ (iD) Ana Paula Matos ${ }^{1}$ \\ (iD) Heron Werner ${ }^{1}$ \\ Edward Araujo Júnior 3
}

\begin{abstract}
1. Departamento de Medicina Fetal, Clínica de Diagnóstico por Imagem (CDPI), Rio de Janeiro, RJ, Brasil 2. Departamento de Radiologia, Universidade Federal do Rio de Janeiro (UFR|), Rio de Janeiro, RJ, Brasil 3. Departamento de Obstetríía, Escola Paulista de Medicina - Universidade Federal de São Paulo (EPM-UNIFESP), São Paulo, SP, Brasil 4. Curso de Medicina, Universidade Municipal de São Caetano do Sul (USCS), Campus Bela Vista, São Paulo, SP, Brasil

E-mail: araujojred@terra.com.br
\end{abstract}

http://dx.doi.org/10.1590/1806-9282.66.4.386

Pregnancy can be associated with a period of distress and psychological vulnerability. The transition to parenting involves fast physical, psychological, and social changes. Stress is the perception of a discrepancy in the availability of resources to meet the demands of external events or stimuli'. Stress and anxiety are highly related and involve systemic responses as cortisol reactivity ${ }^{2}$. Anxiety is the perception of external stimuli to uncertain danger or potential threats and involves an organic response ${ }^{3}$.

The World Health Organization declared COVID-19 as a public health emergency of international concern in January 2020. In Face of the possibility of an uncontrolled outbreak, many cities and countries have established mass quarantine, and public authorities have asked the population to self-isolate at home for weeks. Quarantine involves the loss of freedom, uncertainty over disease status, physical distance from beloved relatives, and boredom. The imposition of quarantine presents psychological costs that cannot be measured and are sometimes neglected ${ }^{4}$.

During the COVID-19 outbreak, pregnant women are experiencing stress and anxiety from the perception of disruption in prenatal services and reduced access to health facilities and medication for themselves and for their newborns ${ }^{5}$, fear of infecting family members and the newborn, boredom, frustration, financial loss, and the effect of the disease or its treatment on the fetus. These perceptions are contrived or enhanced by many reliable and unreliable media sources ${ }^{6}$.

In pregnancy, little is known about the stress in infectious outbreaks and/or quarantine. However, the effects of stress and anxiety during pregnancy and delivery are very well documented and should be expected in the large population of uninfected or asymptomatic pregnant women ${ }^{7}$. The consequences of stress nowadays on these patients may affect the obstetrics and fetal medicine services, and the neonatal intensive care units in a very short period due to increased risks of preterm delivery and low birth weight. Additionally, the effects of anxiety extend to a risk of puerperal complications, such as poor parental bonding and postpartum depression. The long-term effects on a child extend beyond inherited genes and the quality of the pregnancy care and are known as functional teratology or Baker hypothesis. Maternal stress is also linked to interferences in the neurodevelopment of the fetus, which adds to the risk of inherited psychiatric illness ${ }^{8}$. 
Maternal-fetal medicine has developed and achieved great results in the prevention of pregnancy complications through various measures such as early fetal ultrasound, maternal psychological support, and by increasing the maternal-fetal attachment and helping parents to cope with adverse conditions through the prediction and prevention of fetal growth restrictions, preeclampsia, and spontaneous preterm delivery. During the COVID-19 outbreak, maternal-fetal specialists know they have a great task ahead: to continue supporting those suffering from known conditions and to face new, unknown challenges. However, stress and anxiety are well-known threats that silently harm women and future generations and cannot be neglected. Hence, further knowledge about the harmful effects of stress and anxiety during pregnancy is necessary in the future.

\section{REFERENCES}

1. Lazarus RS, Folkman S. Stress, appraisal, and coping. Springer: New York; 1984.

2. Dunkel Schetter C. Psychological science on pregnancy: stress processes, biopsychosocial models, and emerging research issues. Annu Rev Psychol. 2011;62:531-58.

3. Grillon C. Models and mechanisms of anxiety: evidence from startle studies. Psychopharmacology (Berl). 2008;199(3):421-37.

4. Rubin G), Wessely S. The psychological effects of quarantining a city. BMJ. 2020;368:m313.

5. Saulnier DD, Brolin K. A systematic review of the health effects of prenatal exposure to disaster. Int J Public Health. 2015;60(7):781-7.

6. Brooks SK, Webster RK, Smith LE, Woodland L, Wessely S, Greenberg N, et al. The psychological impact of quarantine and how to reduce it: rapid review of the evidence. Lancet. 2020;395(10227):912-20.

7. Lee DT, Sahota D, Leung TN, Yip AS, Lee FF, Chung TK. Psychological responses of pregnant women to an infectious outbreak: a case-control study of the 2003 SARS outbreak in Hong Kong. I Psychosom Res. 2006;61(5):707-13.

8. Monk C, Lugo-Candelas C, Trumpff C. Prenatal developmental origins of future psychopathology: mechanisms and pathways. Annu Rev Clin Psychol. 2019;15:317-44. 